\title{
Pattern of Pediatric Mortality in a Tertiary Hospital in Oman
}

\author{
Mohamed El-Naggari, ${ }^{1,}$ Anas-Alwogud Abdelmogheth, ${ }^{1}$ Hashim Javad, ${ }^{1}$ Khalfan Al Senaidi, ${ }^{1}$ and \\ Ibtisam El Nour ${ }^{1}$ \\ ${ }^{1}$ Department of Child Health, Sultan Qaboos University, Al-Khod 123, Sultanate of Oman \\ "Corresponding author: Dr. Mohamed El-Naggari, Department of Child Health, Sultan Qaboos University, Al-Khod 123, Sultanate of Oman. Tel: +968-98178236, E-mail: \\ mnaggari@yahoo.com
}

Received 2016 June 28; Revised 2016 August 08; Accepted 2016 September 12.

Keywords: Sultan Qaboos Univeristy Hospital, High Dependency Unit, Pediatric Intensive Care Unit, Neonatal Intensive Care Unit, Multiple Organ Dysfunction Syndrome

\section{Dear Editor,}

Pediatric mortality remains a public health priority world-wide, and is amongst factors that reflect the health of children in the population (1). In developing countries, more researches on the nature of the diseases will decrease the burden of preventable deaths. Also, limited health resources motivate health authorities to accomplish new preventive and therapeutic protocols to minimize mortality among pediatric patients (2). In spite of all efforts in promoting children's health, there is not much information on pattern of childhood mortality in Sultanate of Oman.

We carried out a retrospective study on pattern of pediatric mortality among children, who died at Sultan Qaboos Univeristy Hospital (SQUH) from 1st of January 2011 to 31st of December 2012. We studied the influence of age, gender, race, nationality status, time of death and residence on mortality. Cause of death was classified into nonpreventable (present knowledge and technological development cannot prevent these deaths), preventable (cause with modifiable risk factors) and uncertain. Descriptive statistics, median (and Interquartile Ratio (IQR)) and Chisquared tests were performed, wherever appropriate.

During the study period, we had a total of 9649 admissions and 110 deaths. The mortality rate was 11 deaths per 1000 admissions. Among the study population, age ranged from one day to fourteen years, median of 4.9 years and IQR was 9 days to 6.4 years. Overall, $60.9 \%$ of the deceased children were males, which gives a gender ratio of 1.6:1. Most of the death cases were Omani children and only seven (6.4\%) children were non-Omanis $(\mathrm{P}<0.05)$. The residential distribution and time of presentation showed no statistical significance in our center. Furthermore, 52.7\% (58 cases) of the deceased children were from regions other than Muscat area; $48.3 \%(n=28)$ of them occurred during the night shift. The maximum mortality was in the neonatal period
(49\%), with the highest number of deaths overall when tallied across all risk factors. Therefore, the Neonatal Intensive Care Unit (NICU) was the ward with highest recordable deaths and longest duration of stay. Prematurity and neonatal sepsis was the main cause of death (Table1). Infections were the most common primary cause (50\%), and secondary cause of death in $18 \%$ of mortality cases. Infections showed no significant seasonal variation. Across the study, mortality secondary to congenital malformations was $9.1 \%$ (10 cases), which was considered as $18.5 \%$ of the neonatal mortality. Trauma (9.1\%) is a burden to the healthcare system in Oman with motor vehicle collisions making up the bulk of cases (Table 2). We observed that $50 \%$ of the deceased patients were from outside Muscat and 36.4\% occurred during night. Causes of death were classified as $80 \%$ preventable, $18.2 \%$ non-preventable, and $1.8 \%$ uncertain. Preventable causes were further classified as $62.5 \%$ infective and $37.5 \%$ non-infective causes. Preventable deaths had significantly longer hospital stay (82.6\%) and hence consumed more hospital and health resources.

Our mortality data is very close to North American death rate, with national death rate of 8.47 per 1000 live births of Native Americans and 5.33 in non-Hispanic Whites (3). Also, it was significantly low if compared to developing countries, with a fatality rate of $14 \%$ (4). Different studies carried out in developing countries have revealed that the majority of deaths were in the neonatal period. In SQUH, numbers of deliveries and consultation are dramatically increasing. Aravindhakshan et al. found negative impact on neonatal health outcomes by increasing the load of outpatient consultations and number of deliveries (5). In our study, prematurity and congenital malformation were relatively high around $10 \%$ and $9.1 \%$ of the total number of deaths. In Oman, lethal malformations caused 54\% of the neonatal deaths (6). Abdellatif et al. concluded that prematurity, sepsis and congenital malformations were the leading cause of neonatal mortality at SQUH (7). Infection rate 
Table 1. The Relationship Between Age at Death and Duration of Stay, Time of Death, Location of Death and Place of Residence

\begin{tabular}{|c|c|c|c|c|}
\hline \multirow[t]{2}{*}{ Parameters } & \multicolumn{3}{|c|}{ Age at Death n, (\%) } & \multirow[t]{2}{*}{ Total (\%) } \\
\hline & 0 - 28 days & $28 \mathrm{D}-<1 \mathrm{yr}$ & $>1$ year & \\
\hline \multicolumn{5}{|l|}{ Duration of stay } \\
\hline$<24 \mathrm{hrs}$ & $14(25.9)$ & $4(22.2)$ & $9(23.7)$ & $27(24.5)$ \\
\hline 24 hrs $-<7$ D & $22(40.7)$ & $4(22.2)$ & $11(28.9)$ & $37(33.7)$ \\
\hline$>7 \mathrm{D}$ & $21(33.4)$ & $10(55.6)$ & $18(47.4)$ & $46(41.8)$ \\
\hline \multicolumn{5}{|l|}{ Time of death } \\
\hline $8 \mathrm{am}-4 \mathrm{pm}$ & $21(38.9)$ & $4(22.2)$ & $11(28.9)$ & $36(32.7)$ \\
\hline$>4 \mathrm{pm}-12 \mathrm{am}$ & $13(24.1)$ & $5(27.8)$ & $11(28.9)$ & $29(26.4)$ \\
\hline$>12 \mathrm{am}-<8 \mathrm{am}$ & $20(37)$ & $9(50.0)$ & $16(42.2)$ & $45(40.9)$ \\
\hline \multicolumn{5}{|l|}{ Location of death } \\
\hline NICU & $31(57.4)$ & $2(11.1)$ & $0(0.0)$ & $33(30)$ \\
\hline Delivery ward & $14(25.9)$ & $0(0.0)$ & $0(0.0)$ & $14(12.7)$ \\
\hline$A \& E$ & $5(9.3)$ & $6(33.3)$ & $13(34.2)$ & $24(21.8)$ \\
\hline PICU & $1(1.8)$ & $7(38.9)$ & $11(28.9)$ & $22(20)$ \\
\hline Wards & $3(5.6)$ & $3(16.7)$ & $14(36.9)$ & $17(15.5)$ \\
\hline \multicolumn{5}{|l|}{ Residence (Muscat) } \\
\hline Inside & $29(53.8)$ & $7(38.9)$ & $16(42.1 \%)$ & $52(47.3)$ \\
\hline Outside & $25(46.2)$ & $11(61.1)$ & $22(57.9 \%)$ & $58(52.7)$ \\
\hline \multicolumn{5}{|l|}{ Total No. of deaths (\%) } \\
\hline & $54(100)$ & $18(100)$ & $38(100)$ & $110(100)$ \\
\hline
\end{tabular}

Abbreviations: NICU, Neonatal Intensive Care Unit; A\&E, Accident and Emergency; PICU, Pediatric Intensive Care Unit.

Table 2. Distribution of Cause of Death

\begin{tabular}{|lcc|}
\hline Cause of death & Number & $(\%)$ \\
\hline Infection & 55 & 50 \\
\hline Prematurity & 11 & 10 \\
\hline Congenital malformation & 10 & 9.1 \\
\hline Trauma & 10 & 9.1 \\
\hline Cardio-pulmonary arrest & 7 & 6.4 \\
\hline Accidental & 6 & 5.5 \\
\hline Metabolic & 5 & 4.5 \\
\hline Dead on arrival & 2 & 1.8 \\
\hline Hypoxic ischemic encephalopathy & 2 & 1.8 \\
\hline Extensive nasopharyngeal carcinoma & 1 & 0.9 \\
\hline Bleeding esophageal varices, portal hypertension & 1 & 0.9 \\
\hline Total & 110 & 100 \\
\hline
\end{tabular}

was higher than that of other developing countries, where infection (21\%) and respiratory causes (17.2\%) are the main causes of death at tertiary hospitals (8). The majority of our mortality incidences were preventable. Our data showed that preventable deaths were higher than that reported in Yemen and other Asian countries, which have a common demographic and geographical nature with $\operatorname{Oman}(4,9)$.

In conclusion, Pediatric mortality rate in Oman is decreasing and moving towards rates found in developed countries. Omanis have a higher fraction of preventable deaths. Health education about infection control, prevention of accidental or non-accidental injuries and consequences of consanguineous marriage can reduce preventable causes of death. Also, congenital malformation is an important factor in neonatal deaths. Further detailed studies on possible social aspect and the impact of the high prevalence of consanguineous marriage in the Persian Gulf region are needed. Studies on pattern of pediatric mortality in Oman are very limited. This analysis of deaths in children in Oman could act as a baseline study for comparison over time in Oman and other countries in the region. 


\section{Footnotes}

Authors' Contribution: Mohamed El-Naggari was the principle investigator, and participated in the study design, methodology, manuscript writing and statistical analysis; Anas-Alwogud Abdelmogheth was involved in study design and manuscript writing; Hashim Javad contributed in discussions; Khalfan Al Senaidi was involved with data collection; Ibtisam El Nour contributed to discussions.

Financial Disclosure: We had no financial interests related to the material in the manuscript.

Funding/Support: We did not receive any funds or support for our manuscript

\section{References}

1. Moore A. Changing patterns of childhood mortality in Wolverhampton. Arch Dis Child. 2005;90(7):687-91. doi: 10.1136/adc.2004.068460. [PubMed: 15970609].

2. Orne-Gliemann J, Perez F, Leroy V, Newell ML, Dabis F. [A decade of child health research in developing countries]. Sante. 2003;13(2):69-75 [PubMed: 14530116]
3. Wong CA, Gachupin FC, Holman RC, MacDorman MF, Cheek JE, Holve S, et al.American Indian and Alaska Native infant and pediatric mortality, United States, 1999-2009. Am J Public Health. 2014;104 Suppl 3:S320-8. doi: 10.2105/AJPH.2013.301598. [PubMed: 24754619].

4. Sallam AK. Common causes of child mortality in Sana'a, Yemen. Saudi Med J. 2005;26(7):1112-5. [PubMed: 16047064].

5. Aravindhakshan R, Jayalekshmi BR, Sukumar R. Correlation of early neonatal mortality and technical efficiency of regional maternal and child health services in oman. Oman Med J. 2010;25(1):53-4. doi: 10.5001/omj.2010.15. [PubMed: 22125701].

6. Santosh A, Zunjarwad G, Hamdi I, Al-Nabhani JA, Sherkawy BE, AlBusaidi IH. Perinatal mortality rate as a quality indicator of healthcare in Al-dakhiliyah region, oman. Sultan Qaboos Univ Med J. 2013;13(4):54550. [PubMed: 24273665].

7. Abdellatif M, Ahmed M, Bataclan MF, Khan AA, Al Battashi A, Al Maniri A. The patterns and causes of neonatal mortality at a tertiary hospital in oman. Oman Med J. 2013;28(6):422-6. doi: 10.5001/omj.2013.119. [PubMed: 24223246].

8. Tariq M, Jafri W, Ansari T, Awan S, Ali F, Shah M, et al. Medical mortality in Pakistan: experience at a tertiary care hospital. Postgrad Med J. 2009;85(1007):470-4. doi: 10.1136/pgmj.2008.074898. [PubMed: 19734514].

9. Shahid K. Pattern of childhood mortality in sandakan hospital, east malaysia. Internet J Trop Med. 2008;5(1):7. 